The Psychic Life of Power

Theories in Subjection 



\title{
The Psychic Life of Power
}

Theories in Subjection

\author{
Judith Butler
}

Stanford University Press

Stanford, California 
Stanford University Press

Stanford, California

(C) 1997 by the Board of Trustees of the Leland Stanford Junior University

Printed in the United States of America CIP data appear at the end of the book 


\section{Acknowledgments}

This work was generously sponsored by a Humanities Research Fellowship from the University of California at Berkeley. I am grateful to those friends and colleagues who gave incisive readings of some of the chapters: Wendy Brown, William Connolly, David Palumbo-Liu, Kaja Silverman, Anne Norton, Denise Riley, and Hayden White, as well as the students who participated in "Social Subjects / Psychic States" at Berkeley. I thank Adam Phillips for his permission to reprint our exchange from Psychoanalytic Dialogues in this context. I also thank Helen Tartar for her meticulous, intelligent, and thoroughgoing editing, and Gayle Salamon for her assistance with the manuscript. 
